ISSN 1518-3483

Licenciado sob uma Licença Creative Commons

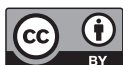

\title{
Narrativas e atividade docente: perspectivas e desafios metodológicos para a pesquisa em educação e formação de professores
}

\section{Narratives and teaching activity: methodological prospects and challenges for research in education and teacher training}

\section{Elieuza Aparecida de Lima ${ }^{[a]}$, Rosane Michelli de Castro ${ }^{[b]}$}

[a] Doutora em Educação pela Universidade Estadual Paulista Júlio de Mesquita Filho (Unesp), docente do Departamento de Didática da Faculdade de Filosofia e Ciências (FFC) da mesma instituição, Marília, SP - Brasil, e-mails: aelislima@ig.com.br; elieuza@marilia.unesp.br

[b] Doutora em Educação pela Universidade Estadual Paulista Júlio de Mesquita Filho (Unesp), docente do Departamento de Didática da Faculdade de Filosofia e Ciências (FFC) da mesma instituição, Marília, SP - Brasil, e-mail: rosanemichelli@marilia.unesp.br

\section{Resumo}

Este texto emerge de nossos percursos de pesquisa e extensão universitárias, a partir de nossas preocupações com a formação inicial e continuada de professores da e para a Educação Infantil e os anos iniciais do Ensino Fundamental. Tivemos, como intenção central, apresentar aspectos de alguns desses encaminhamentos efetivados em busca da criação de possibilidades para a construção coletiva de condições para nutrir todos os envolvidos nos processos investigativos com um conjunto de saberes necessários à tomada de decisões e posicionamentos sobre a e na prática pedagógica. Da ótica 
teórico-metodológica que baseou nossas pesquisas, os processos formativos de professores devem ir ao encontro da expressão das suas ações práticas, a fim de se produzir um novo conhecimento relativizado, entendido com base nas circunstâncias, dos sujeitos e dos lugares sociais daqueles que o elaboram e o disseminam. Essa compreensão foi responsável pelas opções metodológicas feitas para a proposição e o desenvolvimento de nossas pesquisas, prioritariamente a História Oral. Finalmente, concluímos, dentre outros aspectos, que a singularidade do que é realizado, pensado e falado no mundo da escola e, portanto, a prática da pesquisa pedagógica pela via da narrativa é prenhe de conteúdo para projeção de novas ações em favor da melhoria dos processos de ensino e de aprendizagem dirigidos à formação e atuação docentes e à humanização plena de adultos e crianças.

Palavras-chave: Educação. Formação de professores. Narrativas. Atividade docente.

\section{Abstract}

This paper emerges from our research and extension courses university, from our concerns with the initial and continuous training of teachers and the Childhood Education and the early years of elementary school. We had, as a main focus, presenting aspects of some of these referrals effected towards the creation of possibilities for the collective creation of conditions to nourish all those involved in due diligence with a set of knowledge necessary for making decisions and positions on it and in pedagogical practice. Of theoretical and methodological perspective based our research, teacher training processes should meet the expression of their practical actions in order to produce new knowledge relativized, understood based on the circumstances, the social subjects and the social places of those prepare and disseminate. This understanding was responsible for the methodological choices made for the proposition and development of our research, primarily the oral history. Finally, we conclude, among other things, that the uniqueness of what is done, thought and spoken in the world of school and therefore, the practice of educational research through the narrative is full of content for the projection of new shares in favor of improved processes of teaching and learning aimed the formation and activity of teachers and the humanization of adults and children.

Keywords: Education. Teacher training. Narratives. Teaching activity. 


\section{Introdução}

Com Leontiev (1988), vemos a necessidade de que o professor assuma um lugar ativo em seu processo de formação e atuação profissional e que, para isso, será essencial trazer à reflexão e consciência seus saberes, indagações, problemas e desafios do dia a dia escolar.

Concordamos com Martins $(2002,2003)$ que a teoria é expressão de ações práticas. Para essa estudiosa, as pesquisas por meio de contato direto e permanente com professores ${ }^{1}$ nos encaminham para aprendizagens sobre as experiências pedagógicas vividas por eles, recuperadas pela via das narrativas; para a problematização e superação dos problemas postos pela prática, ao mesmo tempo em que se sistematizam novos caminhos para a área.

Martins (2004) assinala que os processos de pesquisa e de ensino fundamentam entendimentos de conhecimento capazes de transgressões em relação à maioria dos modelos anteriores, pois a ação prática se torna o elemento básico para a mediação entre realidade e pensamento. Sobre essa questão, a autora enfatiza: "[...] enquanto nos modelos mais usuais trabalha-se com dois elementos: realidade/pensamento, esse modelo trabalha com três níveis, quais sejam: realidade, ação sobre a realidade e pensamento decorrente dessa prática" (MARTINS, 2004, p. 52).

Em nossa experiência, aprendemos a construção da docência, em grande parte, pela própria prática docente, sem que isso, no entanto, signifique o alijamento de reflexões teóricas mais consistentes. Com essa compreensão, questionamos: a formação docente inicial ou continuada, tal como a apresentamos, pode ser valorizadora da atividade e das vozes dos professores, vislumbrando consciência da própria formação profissional e atuação docente?

$\mathrm{Na}$ tessitura deste artigo, buscamos respostas a essa questão e, para isso, organizamos nossos tateios e experiências em três momentos.

1 As referências aos professores e professoras, feitas neste texto, seja de modo específico ou não,
serão feitas utilizando-se o substantivo masculino "professor" e o genérico masculino "professores". 
Primeiramente, trazemos à reflexão fundamentos teóricos sobre a atividade, o valor das narrativas e suas contribuições para a educação e a pesquisa. Num segundo momento, num mergulho nas vozes dos professores parceiros das pesquisas, tecemos seus anseios, problemas, necessidades e possibilidades, apropriando-nos de conhecimentos ricos e plenos de sentidos para a nossa própria atuação como professoras universitárias e pesquisadoras, possibilitando aos nossos parceiros de trabalho novas significações para sua formação e atuação profissional. Por fim, de maneira (in)conclusa, destacamos algumas perspectivas e desafios em relação à formação de professores, a partir de sua atividade e narrativa.

\section{A atividade e as narrativas: valorização das ações e vozes do professor}

Da ótica teórico-metodológica que baseou nossas pesquisas, os processos formativos de professores devem ir ao encontro da expressão das suas ações práticas, a fim de se produzir um novo conhecimento relativizado, entendido a partir das circunstâncias, dos sujeitos e dos lugares sociais daqueles que o elaboram e o disseminam.

Essa compreensão foi responsável pelas opções metodológicas feitas para a proposição e o desenvolvimento de nossas pesquisas, prioritariamente a denominada História Oral, valorizadora das narrativas dos sujeitos envolvidos e, portanto, como nos desafiamos, também, reveladora dos lugares ocupados pelos professores, muitas vezes, espaços de poucas falas, interlocuções e atividade.

Partimos da ideia de que atividade do professor não se trata de qualquer fazer. Comungamos da posição de Leontiev (1978, p. 269, grifos do autor), considerando suas bases no materialismo dialético:

Devemos sublinhar que esse processo é sempre activo do ponto de vista do homem. Para se apropriar dos objectos ou dos fenômenos que são o produto do desenvolvimento histórico, é necessário desenvolver 
em relação a eles uma actividade que reproduza, pela sua forma, os traços essenciais da actividade encarnada, acumulada no objecto.

Em nossas pesquisas, reafirmamos o papel da atividade na constituição do humano nas pessoas. No caso de nossas pesquisas, almejamos a formação da profissionalidade docente, tendo como ponto de partida e de chegada a atividade do professor, como sujeito intelectual, compositor/autor de sua história, por meio da sua relação com outros homens, adultos e crianças.

Na perspectiva histórico-cultural, ser homem significa ser ativo, com vistas a ser humano. Trata-se de um processo de humanização no qual o homem torna-se cada vez mais autônomo em sua relação com o mundo objetivo, podendo utilizar os conhecimentos apropriados em novos processos de aprendizagem. Nele, o homem amplia seus mecanismos de apropriação tornando-se cada vez mais universal (detentor de conhecimentos cada vez mais complexos), humano, liberto e consciente (de sua ação individual e coletiva). Essencialmente, a atividade educativa e a comunicação condicionam o processo de humanização.

Com a perspectiva de projetar a formação profissional docente em sua plenitude, compreendemos a atividade humana como fundamento das principais transformações qualitativas, em nível psíquico, com possibilidades de o professor dominar sua conduta em níveis cada vez mais sofisticados e de expressar suas aprendizagens por meio de ações e atitudes capazes de tornar o ensino possibilidade de projeções de aprendizagens significativas à humanização de cada criança com a qual ele trabalha. Temos, como entendimento, o homem como ser ativo, que, em processos de educação e de comunicação, sempre caracterizados por sua atividade, se humaniza. Para nós, a comunicação torna-se, assim, elemento de formação humana, considerando as falas, as vozes, as narrativas, como instrumentos de pesquisa, de ensino e de humanização.

Com os estudos de Leontiev (1988), ampliamos nossas compreensões do que seja atividade. De acordo com o autor, atividade é o fazer por meio do qual o sujeito aprende as qualidades que o tornam humano, 
apropriando-se e objetivando conhecimentos, permitindo a ele, de forma cada vez mais consciente e qualitativa, orientar-se no mundo (DAVÍDOV, 1988; LEONTIEV, 1988).

Na relação com o outro, o sujeito apropria-se das ações que compõem a atividade e do seu significado. Com isso, o indivíduo atribuirá sentido aos significados que constituem o conteúdo da atividade, no trabalho colaborativo e em situações de comunicação.

O caráter da atividade humana é social e seu conteúdo está ligado às condições histórico-sociais. Sobre essa questão, ressaltamos que, na ótica da Teoria Histórico-Cultural, a atividade caracteriza-se pelo fazer que se torna vital para o sujeito, no qual coincide o motivo que o leva a agir e o resultado a que ele quer chegar. Desse ponto de vista, a atitude ativa da criança é condição sem a qual as aprendizagens provocadoras do desenvolvimento cultural amplo na infância não se efetivam ou ficam prejudicadas.

Com essa concepção, mergulhamos nossas ações na busca por tornar "visíveis" nossas vozes e as falas dos professores com os quais nos comunicamos, para melhor pensarmos a educação, a atividade docente e as possibilidades de humanização de cada pessoa, seja o adulto, seja a criança.

Daí nossa abordagem metodológica focar-se na História Oral, nas narrativas. A História Oral alicerça-se nos sujeitos, especialmente, em suas narrativas sobre as situações vividas, em suas experiências e história (MEIHY, 2000). Mas, como salienta Teixeira (2004, p. 159), é necessária a compreensão de que não se trata de uma metodologia voltada a apenas aos estudos do passado, "[...] mas também do tempo presente, do contemporâneo". Partilhamos com a estudiosa o seguinte pensamento:

Na medida em que o foco de seus trabalhos está na oralidade e não necessariamente no resgate do passado e tendo em vista que vamos ao passado interrogando-o com as questões do presente e possibilidades de futuro, as temáticas e indagações do presente e o tempo presente em si mesmo são o vértice do trabalho com esta metodologia (TEIXEIRA, 2004, p. 159).

Conforme assevera Cunha (1997), o universo de pesquisas que se utilizam das narrativas como metodologia privilegiada, tanto na 
pesquisa quanto no ensino, tem-se ampliado. Sendo assim, acreditamos que os nossos trabalhos possam oferecer contribuições a tal movimento, quando afirmamos, a exemplo de Cunha (1997, p. 5), que nossas ações de ensino, pesquisa e extensão universitárias também estiveram pautadas no diálogo entre a prática vivida e as construções teóricas formuladas nessas práticas e sobre essas práticas. Isto é, no entendimento de reflexão-ação explicitada por Pérez Gómez (1992, p. 103), em que se considera o professor "[...] o sujeito da análise que faz de seu próprio cotidiano, implicando a imersão consciente do homem no mundo de sua experiência, num mundo carregado de conotações, valores, intercâmbios simbólicos, correspondências afetivas, interesses sociais e cenários políticos".

Compreendemos, assim, que são estreitos os laços entre História Oral e educação, porque que se trata de uma ação educativa, pedagógica e de um ato político.

A História Oral teve sua origem nos Estados Unidos da América, nos anos de 1920 e 1930, com a denominada Sociologia de Chicago, principalmente com os trabalhos sobre Histórias de Vida - recurso metodológico vinculado à História Oral, enfatizada a partir da perspectiva do observador. Junto com a observação participante, dá sentido à noção de processo, uma vez que capta e tenta compreender, no processo de interação, como se constrói a vida dos sujeitos (MACEDO, 2006).

Essa metodologia tem sido definida por alguns autores como metodologia, como técnica e como fonte para a pesquisa social, cuja base é a oralidade. Sabemos que todos os três elementos estão presentes nela, no entanto, concebemos a História Oral como algo mais amplo, que, mediante o olhar pedagógico, pode se apresentar também como processo educativo. Nessa perspectiva, compreendemos a História Oral não apenas como uma metodologia, uma técnica ou fonte, conforme propõe alguns autores, mas como um "movimento" (TEIXEIRA, 2004).

Como metodologia, a História Oral reúne, propõe e contém um conjunto de pressupostos teórico-epistemológicos que fundamentam e norteiam a construção da pesquisa e da investigação dos fenômenos da vida humana e social. Sustentada em tais pressupostos, envolve o que caracterizamos como 
abordagens qualitativas, reconhecendo os sujeitos como seres de memória, cultura e história, os quais interpretam, refletem, significam e ressignificam o mundo e suas experiências. São sujeitos que elaboram conhecimentos próprios, interpretações e sistemas de significações, que tanto podem revelar como esconder informações, conforme seus interesses e conveniências. Basear-se no sujeito falante é um dos fatores que justifica a centralidade da narrativa no trabalho com História Oral (TEIXEIRA, 2004).

Como técnica, a História Oral propõe um conjunto de estratégias para a investigação, também focando a oralidade e as diferentes formas de apreendê-la e registrá-la. Nessa proposta, as entrevistas livres e semiestruturadas, gravadas ou filmadas, representam o seu principal instrumento ou estratégia de abordagem dos sujeitos na pesquisa, seja para compor a chamada História Oral Temática, seja para os Relatos orais de Vida, dentre outras de suas vertentes. Além da preparação e da realização das entrevistas, essa técnica exige a transcrição, interpretação e análise dos dados coletados por meio dela, observando-se aspectos técnicos a esse respeito, além dos que se referem à classificação e catalogação do material recolhido, ao seu arquivamento e conservação, e ainda à sua restituição ao público, à sociedade.

Quando gravadas, as fitas de áudio e os filmes em vídeos das entrevistas e depoimentos e suas respectivas transcrições tornam-se, então, documentos. São fontes para a pesquisa histórica ou para outros tipos de estudo. Trata-se de uma fonte produzida pelo próprio pesquisador, diferentemente de outras fontes já existentes, que os pesquisadores ou pesquisadoras levantam, identificam, contextualizam e classificam, para sua utilização e análise. Por isso, a História Oral é também definida como fonte (TEIXEIRA, 2004).

Contudo, resgatando a ideia de que a História Oral, além de uma metodologia, uma técnica e uma fonte é também um movimento, ela se torna uma experiência de caráter pedagógico, uma vez que sua ação é formadora: serve não só para interrogar e registrar, mas potencializar a condição e ação dos sujeitos no mundo. "Nos fios da memória, no resgate do vivido, ressignificado, reinterpretado, revivido na narrativa, os sujeitos produzem 
conhecimentos e vão se constituindo em processos de identificação e de subjetivação. Em processos de formação" (TEIXEIRA, 2004, p. 160).

$\mathrm{Na}$ relação intersubjetiva estabelecida entre sujeito de pesquisa e pesquisadores, os primeiros emprestam àqueles que ouvem suas vidas e histórias. Não se trata, pois, de buscar uma única verdade na fala dos sujeitos, mas as significações presentes na fala desses sujeitos. Isso significa que o foco reside no sentido que os sujeitos atribuem ao mundo, às suas experiências inseridas em uma cultura e processo sócio-histórico. Conforme afirma Teixeira (2004), a vida, a fala, a escuta sensível e acurada e a memória são os fios da tessitura da História Oral.

Ao falarem de suas vidas, contarem suas histórias, relatarem experiências de trabalho, em tempo/espaço de formação, os professores buscam suas reminiscências e lembranças e, nelas, as interpretações, os sentidos atribuídos, os conhecimentos gerados. Por esse motivo, a memória se torna uma de suas vigas e, nesse sentido, constituem a História Oral. Ao falarem de si, do que pensam, vivenciando diálogos ou em outras experiências discursivas em que os professores trocam experiências, mediante seus relatos, dá-se o processo formativo pela via da narrativa (TEIXEIRA, 2004).

Desse modo, o sujeito reflete sobre o social, mediatizando-o e transportando-o para o campo da subjetividade, elemento precioso que compõe a vida, uma dimensão humana a ser interrogada e compreendida. A pesquisa representa, nesse sentido, uma relação intersubjetiva entre sujeitos que falam e ouvem, que sentem e pensam, unindo ciência e afeto, razão e emoção. Nesse contexto, cabe ao pesquisador buscar a informalidade, a espontaneidade e a confiança dos sujeitos que emprestam suas vidas e histórias, lhe confiam lembranças, sentimentos, pensamentos e sonhos. Trata-se de um encontro entre diferentes registros culturais, exigindo do pesquisador um permanente exercício de alteridade, fina escuta, permitindo um diálogo sensível e fecundo (MACEDO, 2006).

A História Oral revela-se como movimento pedagógico, tanto do ponto de vista individual como do coletivo, e nisso está a maior de suas virtualidades para a educação. Compactuamos com Teixeira (2004, p. 164): 
Por estas trilhas, nestas impregnações, a História Oral se faz Educação e a Educação faz História Oral. Aqui se revelam suas mais íntimas ressonâncias, originadas na História Oral como um trabalho como um movimento de subjetivação, de reconstituição de identidades: um permanente e profícuo movimento. Processos, movimentos de significação ressignificação e da reconstituição do vivido, da experiência narrada como aquilo que nos passa, muito além do que se passa. Processos de formação humana, em uma palavra: Educação.

Com esses pressupostos orientadores das nossas opções teóricas e metodológicas, convidamos a participarem da execução das nossas pesquisas professores de escolas públicas da região de Marília, SP - atuantes em escolas de Educação Infantil e Ensino Fundamental - e também professores em formação inicial do curso de Pedagogia da Faculdade de Filosofia e Ciências - Unesp, Campus de Marília, SP.

A escolha desses parceiros-professores de escolas públicas como sujeitos e de escolas públicas como lócus da investigação se deve ao grande desafio enfrentado por esses educadores brasileiros, nesses locais: organizarem práticas pedagógicas que resultem em aprendizagens e, consequentemente, em humanização de crianças, jovens e adultos (CHAVES, 2008). Afinal,

[...] a ação do Educador, independente de sua formação ou condição de trabalho, expressa a concepção de homem [criança, infância] de sociedade e de educação que se tem e a que se projeta. [...] seja qual for o local onde se efetive a ação escolar - no interior do Piauí ou nos rincões gaúchos, ela expressa uma concepção de Educação (CHAVES, 2008, p. 76).

Essa diretriz orientou nossas atitudes e ações e, por meio dela, esses professores foram convidados a sistematizarem coletivamente o conhecimento acerca dos processos educativos que ocorrem nas escolas onde atuam, e a proporem ações para o aprimoramento desses processos.

Os profissionais docentes em formação continuada nas escolas foram chamados a narrarem sobre seus entendimentos de mundo e acerca das situações vividas por eles com outros docentes, em momentos de trocas de 
experiências pedagógicas. Abrimos o convite para que eles se reconhecessem como seres capazes de narrar, de transmitir, de registrar, e de reelaborarem experiências docentes vividas, a participarem de mais esse processo pedagógico formativo coletivo com os professores em formação inicial no Curso de Pedagogia, em busca da superação dos problemas postos pela prática. Em decorrência, tudo o que for materialização de conhecimento passa a ser visto, como anuncia Martins (2004), como objeto a ser trabalhado coletivamente e sobre o qual se toma consciência para renovadas ações e atitudes.

Especificamente, projetamo-nos para viabilizar processos e situações formativas integradoras da dimensão prática das escolas e seus profissionais, com a dimensão teórica dos centros acadêmicos e seus sujeitos em formação; favorecer a incorporação da dimensão coletiva, social e cultural nos processos dirigidos à formação de professores; e investigar as ações docentes, a partir de quatro núcleos básicos, a saber:

1) Os recursos e as formas de organização do trabalho pedagógico na escola. Este núcleo envolveu investigação quanto:

- à estrutura física: localização, instalação, recursos materiais e humanos, número de turnos de funcionamento, salas de aula em funcionamento e de alunos por sala;

- à organização do trabalho escolar: estrutura administrativa e pedagógica, relações de poder, formas e processos de participação e gestão;

- ao corpo discente: nível socioeconômico-cultural;

- ao corpo docente: situação funcional, tempo de serviço, tempo na escola;

- aos problemas enfrentados pela escola.

2) As perspectivas teóricas às quais as práticas dos professores se encontram vinculadas. Este núcleo permite a reflexão sobre práticas como sendo resultados de orientação teórica específica que, por sua vez, estão presentes em um projeto político próprio. Contemplou quanto: 
- à concepção de homem, de mundo, de conhecimento;

- ao papel da escola;

- aos pressupostos de aprendizagem;

- à concepção de ensino.

3) O ensino nas salas de aula. Este núcleo englobou todos os elementos dos processos de ensino e de aprendizagem que são ponto de partida para análise da ação docente e ponto de retorno para constante sistematização. Englobou investigação quanto:

- à dimensão cognitiva, socioeconômica, afetiva e cultural dos alunos;

- às condições de vida e de trabalho, formação e práticas dos professores;

- à escolha de atividades de ensino diferenciadas e técnicas variadas;

- à relação educador/educando: disciplina e indisciplina;

- ao planejamento e avaliação do ensino e da aprendizagem: as várias etapas.

4) As propostas para reconstrução da prática pedagógica. Neste núcleo, focamos todas as proposições para reconstruir o ensino sistematizado e a prática pedagógica da escola. Tais proposições puderam ser elaboradas e discutidas ao mesmo tempo em que se fez a análise crítica das situações de ensino e das condições de trabalho na escola, mas puderam também envolver propostas mais amplas de reconceitualização total da prática docente. Envolveu investigação quanto:

- à gestão democrática;

- ao trabalho coletivo;

- à construção do projeto pedagógico. 
Em face do exposto, apresentamos a seguir alguns resultados do complexo e desafiante processo de dar "voz" e "lugar ativo" aos professores, por meio de reflexões realizadas pelo conjunto dos sujeitos envolvidos, mirando algumas propostas de ações para as situações teorizadas pelo grupo de sujeitos.

\section{Mergulhos e aprendizados: as vozes dos professores}

Embasadas na compreensão de que a docência, intencional e potencialmente humanizadora, exige posicionamento político expressado em atuação ativa e consciente do professor, em qualquer nível da escolaridade - e que, conforme defende Ivana Jinkings, na apresentação do livro A Educação para Além do Capital, de Mészáros (2008, p. 9, grifos do autor), “[...] educar é - citando Gramsci - colocar fim à separação entre Homo faber e Homo sapiens; é resgatar o sentido estruturante da educação e de sua relação com o trabalho, as suas possibilidades criativas e emancipatórias" -, esse processo requer que o professor seja agente de sua prática, sujeito intelectual e participativo, capaz de planejar e de se projetar para a construção de outro mundo possível, por meio da educação.

Em nossas práticas de pesquisa e extensão universitárias, quando interrogados sobre a importância do conhecimento (emancipador), os professores parceiros das nossas ações investigativas consideraram que essa importância está atrelada ao oferecimento de possibilidades de participação dos homens na sociedade, para melhores condições de vida.

V: O conhecimento é importante pra se aprimorar, aperfeiçoar nas condições humanas da vida, melhorar as condições de vida, através do conhecimento do homem se vai evoluir e ter melhores condições de vida, se relacionar, interagir com o mundo.

F: O conhecimento é importante na vida das pessoas. É... eu acho que, pra ele é vivenciar, estar em sociedade, participar, que se ele conhece, ele não vai 
ficar fora do que está acontecendo, ele vai poder participar da sociedade com esse conhecimento.

S: Porque eu acredito, assim. Se as pessoas conhecessem seus deveres e o direito dela, ela vê que ninguém vai conseguir, vai passar a perna nela e ela vai conseguir ser um cidadão crítico, reflexivo e não ser manipulado por nenhum outro, nenhuma pessoa.

De fato, essas falas são reveladoras. Dentre outras compreensões, expressam a emergência de que o trabalho do professor seja também ele emancipador, ampliando os significados da apropriação do conhecimento para a humanização das pessoas, caracterizando igualmente o valor do acesso à cultura em sua riqueza e plenitude, para que todos satisfaçam suas necessidades. Assim, concordamos com Timiriazev (1949 apud LEONTIEV, 1978, p. 264) que:

Toda a actividade racional do homem não é senão uma luta, a luta contra a luta pela existência. "É um combate para que todas as pessoas na Terra possam satisfazer as suas necessidades, para que não conheçam nem a indigência, nem a fome, nem a morte lenta" [...].

Nessa medida, seria possível redimensionar o papel da educação escolar, como possibilidade de que as jovens gerações não conheçam a indigência e qualquer tipo de miséria, dentre os quais a cultural.

As narrativas dos professores retrataram ainda entendimentos sobre qual o papel da escola nos dias atuais.

V: [...] os conteúdos historicamente construídos na sociedade vêm pra escola, e faz parte da escola, também. Mas, o que mais tem mudado, significativamente, é a forma de estar passando esse conteúdo, fazendo com que a criança desperte o interesse e construa o seu conhecimento, e, a partir disso, nós vamos interagindo com ela, vai evoluindo o conhecimento que ela já trás de casa, do seu ambiente, e na escola é aprimorado através de outra metodologia que considera todo o conhecimento que ela já tem. 
[...] A escola tem o papel, faz a parte do aprimoramento dos conhecimentos que a criança já tem e disponibiliza todo o tipo de conhecimento que a escola possui e a sociedade, essa criança enquanto ser social e cidadão.

E: O papel da escola, como eu disse anteriormente, é de levar o ensino sistematizado pras crianças, para que elas possam, na vida, viver em sociedade.

S: O papel da escola é formar, mas, antes de tudo, a gente estava sendo mais, educando do que transmitindo conhecimento, apesar que, lá fora, a criança já vem com uma bagagem muito avançada. Aqui, a gente só frisa um pouquinho, mas eu acho que o trabalho da escola ainda é ensinar.

Das expressões desses profissionais, pode-se inferir que, para eles, cabe à escola a transmissão de saberes - conteúdos historicamente construídos pelos homens -, por intermédio de ensino sistematizado, em busca de ampliar o conjunto de conhecimentos que as crianças já têm e de outras vivências fora da escola. Essas considerações nos desafiam a resgatar, fundamentadas nas proposições da Teoria HistóricoCultural, que somente o acesso à escola não é condição suficiente para a humanização das pessoas e tampouco a "mera transmissão de conhecimentos". Sobre essa questão, retomamos Alana Jinkings, em seu texto de apresentação de A Educação para além do capital (MÉSZÁROS, 2008): para ela, o que está em jogo é a educação escolar como possibilidade de "[...] tirar das sombras do esquecimento social milhões de pessoas" com sede de conhecimento libertador da situação de miséria cultural e social de homens e mulheres.

Trata-se de uma educação para a libertação. Educação como fonte de possibilidades para humanização de adultos e crianças capazes de, por meio dela, reconhecerem-se como sujeitos de suas práticas, forjados na luta pela existência plena, conscientes da necessidade de rompimento com a lógica social (do capital). Uma lógica perversa que venda os olhos, onde uns poucos se fartam da riqueza cultural e outros milhares morrem de fome de apropriação de bens culturais historicamente produzidos e relacionados às artes, à filosofia, às ciências. 
Quanto às possibilidades de aplicação da teoria apreendida nos cursos de Pedagogia à prática pedagógica, os professores apresentaram diferentes opiniões. Especialmente, atribuíram a possibilidade ou não dessa aplicação a fatores referentes, sobretudo, à organização da escola.

F: É possível, mas acredito que é um pouco difícil. Devido às várias condições que a escola apresenta. Mas é possível [...] a gente tem que adequar de acordo com a realidade. Mesmo, assim, algumas coisas dão para aplicar.

ROB: Muita coisa que eu aprendi eu tento aplicar, mas nem sempre eu consigo aplicar da maneira como eu gostaria. Eu tento fazer o máximo, mas nem sempre dá para fazer. E, eu acho que tudo o que eu faço poderia ser melhor, mas eu tento seguir o que eu aprendi na faculdade, mas, muitas vezes, eu não alcanço aquilo que eu acredito que poderia ser ideal.

J: Eu acho que é possível sim, se fosse diferente a organização da escola. Seria totalmente possivel, eu acredito, tenho certeza, porque o jeito como está a escola organizada não dá. Estava falando com a V., terrível! A gente não pode inventar nada, nada de diferente, não pode!

As expressões dos professores denunciam a lógica da escola, manifestada na sua organização baseada nos moldes da sociedade mercantil, na qual cada profissional parece se limitar a fazer uma parcela do processo, sem necessidade de conscientização das implicações de suas ações para a formação do novo homem e de uma nova sociedade.

Com isso, esses profissionais assinalam a emergência de (re) pensarmos o papel da escola e sua organização, no conjunto de revisões conceituais e práticas necessárias para a educação vir a ser possibilidade de formação de pessoas socialmente ricas e humanizadas, como esperava e defendia Marx (MÉSZÁROS, 2008, p. 47). Essa emergência está intrinsecamente ligada às possibilidades de formação cultural, rica e plena, dos professores - sujeitos capazes de narrarem e de tomarem 
consciência de sua formação e atuação, em busca da superação da lógica perversa do capital.

\section{Considerações finais: convite para novas ações e diálogos}

Este fim é acessível. Mas só o é em condições que permitam libertar realmente os homens do fardo da necessidade material, de suprimir a divisão mutiladora entre trabalho intelectual e trabalho físico, criar um sistema de educação que lhes assegure um desenvolvimento multilateral e harmonioso que dê a cada um a possibilidade de participar enquanto criador em todas as manifestações da vida humana (LEONTIEV, 1978, p. 284).

Ao encontro dessa defesa de Leontiev (1978, p. 284), entendemos que a educação é uma possibilidade de libertação de homens, adultos e crianças, da "divisão mutiladora" do trabalho intelectual e físico. Essa libertação pode encontrar motivação já na criação efetiva de condições de as nossas escolas serem lugares de atividade intelectual dos professores, voltados consciente e intencionalmente para a formação plena das jovens gerações.

Nos limites desta breve exposição, amparadas nas afirmações de Leontiev (1978, p. 284), concluímos este diálogo, embora não permanentemente, elaborado a partir de aspectos extraídos da prática de professores de escolas do ensino básico, narradores e partícipes das reflexões realizadas por todos os sujeitos envolvidos nas pesquisas ora compartilhadas.

A ideia é a de que este texto possa suscitar, ao mesmo tempo, reflexões para o início de novos estudos e embasamento teórico para a implementação de ações projetadas para superação de obviedades, individualismos e fatalismos muito próprios do sistema capitalista no qual a escola se insere, (re)significadas por nós, professoras-pesquisadores, e por nossos parceiros de interlocução e discussões, os professores de crianças da Educação Infantil e dos anos iniciais do Ensino Fundamental.

Os aspectos da prática docente relatados pelos professores em formação continuada reavivaram em todos nós o compromisso político 
com um ensino público de qualidade ${ }^{2}$ e, sobretudo, com uma prática didático-pedagógica voltada para a promoção desse ensino potencialmente humanizador e emancipador.

Nesse sentido, o diálogo com os professores em formação continuada revela que as escolas públicas, mesmo com todos os seus condicionantes limitadores, ainda representam espaços de luta de melhoria para as classes populares. Mesmo com todas as pressões nesses espaços, há a esperança e o otimismo com relação ao papel desempenhado pelas escolas e seus sujeitos.

Em acréscimo, é possível considerarmos que a singularidade do que é realizado, pensado e falado no mundo da escola e, portanto, da prática da pesquisa pedagógica pela via da narrativa, permite que os sujeitos afirmem a importância do local de trabalho, da escola, como também a associação dos diferentes espaços e tempos vividos, influenciadores dos saberes e fazeres e, desse modo, da formação e consequente atuação docentes prenhes de conteúdo para projeção de novas ações em favor da melhoria dos processos de ensino e de aprendizagem dirigidos à humanização plena de adultos e crianças.

\section{Referências}

CHAVES, M. Intervenções pedagógicas e promoção da aprendizagem da criança: contribuições da psicologia histórico-cultural. In: FAUSTINO, R. C.; CHAVES, M.; BARROCO, S. M. S. (Org.). Intervenções pedagógicas na educação escolar indígena: contribuições da teoria histórico-cultural. Maringá: Eduem, 2008. p. 75-89.

CUNHA, M. I. da. Conta-me agora! As narrativas como alternativas pedagógicas na pesquisa e no ensino. Revista da Faculdade de Educação, v. 23, n. 1-2, jan./dez. 1997. Disponível em: <http://www.scielo.br/scielo.php?script=sci_arttext\&pid $=$ S0102-25551997000100010 >. Acesso em: 17 jan. 2011.

\footnotetext{
2 A ideia de qualidade a que ora se recorre é decorrente das reflexões sobre o que se julgou ser necessário e possível para uma educação e um ensino que promovam a emancipação do sujeito, na sociedade.
} 
DAVÍDOV, V. La enseñanza escolar y el desarrollo psíquico: investigación psicológica teórica y experimental. Moscou: Editorial Progreso, 1988.

LEONTIEV, A. N. O desenvolvimento do psiquismo. Lisboa: Livros Horizonte, 1978.

LEONTIEV, A. N. Uma contribuição à teoria do desenvolvimento da psique infantil. In: VYGOTSKY, L. S.; LURIA, A. R.; LEONTIEV, A. N. Linguagem, desenvolvimento e aprendizagem. São Paulo: Ícone, 1988. p. 59-83.

MACEDO, R. S. A etnopesquisa e a apropriação do método. In: MACEDO, R. S. Etnopesquisa crítica etnopesquisa-formação. Brasília: Liber Livro, 2006. p. 81-150.

MARTINS, P. L. O. Princípios didáticos na ação docente: conhecimento como expressão da ação humana. In: ROMANOWSKI, J. P.; MARTINS, P. L. O.; JUNQUEIRA, S. R. A. (Org.). Conhecimento local e conhecimento universal: pesquisa, didática e ação docente. Curitiba: Champagnat, 2004. p. 43-57.

MARTINS, P. L. O. A didática e as contradições da prática. 2. ed. Campinas: Papirus, 2003.

MARTINS, P. L. O. Didática teórica/didática prática: para além do confronto. 7. ed. São Paulo: Loyola, 2002.

MEIHY, J. C. S. B. Manual de história oral. 3. ed. São Paulo: Loyola, 2000.

MÉSZÁROS, I. A educação para além do capital. Trad. Isa Tavares. 2. ed. São Paulo: Boitempo, 2008. (Mundo do trabalho).

PÉREZ GÓMEZ, A. O pensamento prático do professor: a formação do professor como profissional reflexivo. In: NÓVOA, A. (Org.). Os professores e sua formação. Lisboa: Dom Quixote, 1992. p. 93-114. 
TEIXEIRA, I. A. C. História oral e educação: virtualidades, impregnações, ressonâncias. In: ROMANOWSKI, J. P.; MARTINS, P. L. O.; JUNQUEIRA, S. R. A. (Org.). Conhecimento local e conhecimento universal: pesquisa, didática e ação docente. Curitiba: Champagnat, 2004. p. 153-165.

Recebido: 20/02/2013

Received: 02/20/2013

Aprovado: 22/06/2013 Approved: 06/22/2013 